\title{
Study of thermodynamic and acoustic properties of niacin in aqueous hexylene glycol and propylene glycol at different temperatures
}

\author{
Nabaparna Chakraborty, ${ }^{1}$ Kailash Chandra. Juglan ${ }^{1 *}$, Harsh Kumar ${ }^{2 *}$ \\ ${ }^{1}$ Department of Physics, Lovely Professional University, Phagwara, 144401, \\ Punjab, India.
}

${ }^{2}$ Department of Chemistry, Dr. B R Ambedkar NIT, Jalandhar 144 011, Punjab, India

*Corresponding authors e-mail: kc.juglan@1pu.co.in, h.786.man@gmail.com

\section{Supporting Information}

\subsection{Partial molar volume of transfer}

The volumes of transfer for glycols from water to aqueous niacin solutions have been calculated at infinite dilution using the following formula-

$\Delta V_{\phi}^{0}=V_{\phi}^{0}\left(\right.$ in aqueous Niacin) $-V_{\phi}^{0}$ (water)

In Table $\mathbf{S 1}$ the calculated $\Delta V_{\phi}^{0}$ values are indexed and they are all having negative values except for few values i.e. for PG at $308.15 \mathrm{~K}$ throughout all the concentrations of niacin and $\mathrm{HG}$ at $303.15 \mathrm{~K}$ only for $0.01 \mathrm{~mol} \cdot \mathrm{kg}^{-1}$ concentration of niacin. This numerical behavior implies that the molecular interaction of niacin with $(\mathrm{PG} / \mathrm{HG})$ is stronger than the interactions of water with $(\mathrm{PG} / \mathrm{HG})^{1}$. Also, $\Delta V_{\phi}^{0}$ values suggest that the contribution of solute-solute interaction is negligible in the liquid system. From co-sphere overlap model ${ }^{2,3}$ it is found that numerous interactions are taking place inside the mixture which are ion-hydrophilic, hydrophilic-hydrophilic, ion-hydrophobic, and hydrophobichydrophobic interactions. Regarding this model, the negative $\Delta V_{\phi}^{0}$ values are contributed by ion-hydrophobic and hydrophobic- hydrophobic interactions, and the positive values are accounted for ion-hydrophilic and hydrophilic- hydrophilic interactions ${ }^{4,5}$. 


\section{Table S1}

Partial molar volumes of transfer $\Delta V_{\phi}^{0}$, of glycols in the aqueous solution of niacin at different temperatures.

\begin{tabular}{ccccc}
\hline${ }^{\mathrm{a}} m_{B} /\left(\mathrm{mol} \cdot \mathrm{kg}^{-1}\right)$ & \multicolumn{4}{c}{$\Delta V_{\phi}^{0} \times 10^{6} /\left(\mathrm{m}^{3} \cdot \mathrm{mol}^{-1}\right)$} \\
\cline { 2 - 4 } & $T=293.15 \mathrm{~K}$ & $T=298.15 \mathrm{~K}$ & $T=303.15 \mathrm{~K}$ & $T=308.15 \mathrm{~K}$ \\
\hline 0.01000 & -0.26 & $\mathrm{PG}$ & 0.20 \\
0.03000 & -0.14 & -0.17 & -0.31 & 0.32 \\
0.05000 & -0.05 & -0.16 & -0.22 & 0.48 \\
0.01000 & -0.06 & -0.36 & -0.09 & \\
0.03000 & -0.13 & -0.25 & 0.06 & -0.26 \\
0.05000 & -0.36 & -0.80 & -0.29 & -0.52 \\
\hline
\end{tabular}

${ }^{a} m_{B}$ is the molality of aqueous niacin. 


\subsection{Temperature-dependent partial molar volume}

At infinite dilution, the difference in apparent molar volumes as the function of temperature can be evaluated using the following equation-

$$
V_{\phi}^{0}=a+b\left(T-T_{r e f}\right)+c\left(T-T_{r e f}\right)^{2}
$$

The empirical constants are represented by $a, b$ and $c$, the experimental temperature is represented by $T$ and reference temperature by $T_{\text {ref }}$ as $T_{r e f}=298.15 \mathrm{~K}$. In Table $\mathbf{S 2}$ the evaluated empirical constant values are displayed. The coefficient $c$ values are hardly crucial, are all positive except for two values of $\mathrm{HG}$ at $(0.03$ and 0.05$) \mathrm{mol} \cdot \mathrm{kg}^{-1}$ concentration of niacin. By the means of these empirical constants, the theoretical values of $V_{\phi}^{0}$ are calculated and are compared with their experimental values ${ }^{6,7}$. From these comparisons, the deviations of the experimental values from theoretical values are obtained and is termed as ARD $(\sigma)$ and listed in the same table. This parameter is determined using the following formula

$$
\sigma=(1 / \mathrm{n}) \Sigma\left[\operatorname{abs}\left(\left(\mathrm{Y}_{\text {Exptl. }}-\mathrm{Y}_{\text {Calc. }}\right) / \mathrm{Y}_{\text {Exptl. }}\right)\right]
$$

The partial molar volume $\left(V_{\phi}^{0}\right)$ is represented by Y. After all very less deviations are attained, it can be considered that these variations fit properly in the polynomial equation evident from $R^{2}$ values [30]. $V_{\phi}^{0}$ aimed to attain the partial molar expansibilities values using the undermentioned equation

$$
E_{\phi}^{0}=\left(\partial^{2} \mathrm{~V}_{\phi} / \partial \mathrm{T}^{2}\right)_{p}=b+2 c\left(T-T_{r e f}\right)
$$

At infinite dilution, the partial molar expansibilities i.e. $E_{\phi}^{0}=\left(\partial^{2} \mathrm{~V}_{\phi} / \partial \mathrm{T}^{2}\right)_{p}$ are treated as a significant parameter to measure the solute-solvent interactions taking place inside the system. A general thermodynamic equation is established by Hepler ${ }^{8}$ which estimates the extent of solute as structure breaker and structure maker in any mixture with a solvent. The expression is given as-

$$
\left(\partial \mathrm{E}_{\phi}^{0} / \partial \mathrm{T}\right)_{P}=\left(\partial^{2} \mathrm{~V}_{\phi} / \partial \mathrm{T}^{2}\right)_{p}=2 c
$$

In Table S3, the values of $\left(\partial \mathrm{E}_{\phi}^{0} / \partial \mathrm{T}\right)_{P}$ are presented and its sign determines whether the dissolved solute has structure making or structure breaking tendency. $\left(\partial \mathrm{E}_{\phi}^{0} / \partial \mathrm{T}\right)_{P}$ values are all positive, which implies the structure making capacity of solutes ${ }^{8,9}$. In the same table, $E_{\phi}^{0}$ values are also mentioned which are partially positive and partially negative at all temperatures and concentration if niacin. The positive $E_{\phi}^{0}$ values imply the contribution of solute-solvent interaction in the mixture ${ }^{10}$. Also, this can be attributed due to the packing or 
caging effect ${ }^{11}$ between the molecules of niacin and glycols, which describes the interactions among them. 


\section{Table S2}

Values of empirical parameters of Eq. 4, of glycols in aqueous solution of niacin at different temperatures.

\begin{tabular}{|c|c|c|c|c|c|}
\hline${ }^{a} m_{B} /\left(\mathrm{mol} \cdot \mathrm{kg}^{-1}\right)$ & $\begin{array}{c}a \times 10^{6} /\left(\mathrm{m}^{3} \cdot \mathrm{mol}^{-}\right. \\
1)\end{array}$ & $b \times 10^{6} /\left(\mathrm{m}^{3} \cdot \mathrm{mol}^{-1} \cdot \mathrm{K}^{-1}\right)$ & $\begin{array}{c}c \times 10^{6} /\left(\mathrm{m}^{3} \cdot \mathrm{mol}^{-1} \cdot \mathrm{K}^{-}\right. \\
2)\end{array}$ & $R^{2}$ & $A R D$ \\
\hline \multicolumn{6}{|c|}{ PG } \\
\hline 0.01000 & 73.20 & 0.008 & 0.004 & 0.9999 & 0.00109 \\
\hline 0.03000 & 73.25 & 0.003 & 0.006 & 0.9999 & 0.00078 \\
\hline 0.05000 & 73.19 & -0.003 & 0.009 & 0.9999 & 0.00185 \\
\hline \multicolumn{6}{|c|}{$\mathrm{HG}$} \\
\hline 0.01000 & 116.29 & 0.006 & -0.001 & 0.9999 & 0.00086 \\
\hline 0.03000 & 115.86 & -0.031 & 0.005 & 0.9999 & 0.00144 \\
\hline 0.05000 & 115.56 & -0.044 & 0.006 & 0.9999 & 0.00156 \\
\hline
\end{tabular}

${ }^{a} m_{B}$ is the molality aqueous of niacin. 


\section{Table S3}

Partial molar expansibilities, $E_{\phi}^{0}$, for glycols in the aqueous solution of niacin at different temperatures.

\begin{tabular}{|c|c|c|c|c|c|}
\hline \multirow{2}{*}{$\begin{array}{c}{ }^{a} m_{B} / \\
\left(\mathrm{mol} \cdot \mathrm{kg}^{-1}\right)\end{array}$} & \multicolumn{4}{|c|}{$E_{\phi}^{0} \times 10^{6} /\left(\mathrm{m}^{3} \cdot \mathrm{mol}^{-1} \cdot \mathrm{K}^{-1}\right)$} & \multirow{2}{*}{$\begin{array}{c}\left(\partial E_{\phi}^{0} / \partial T\right)_{p} / \\
\left(\mathrm{m}^{3} \cdot \mathrm{mol}^{-1} \cdot \mathrm{K}^{-2}\right)\end{array}$} \\
\hline & $T=293.15 \mathrm{~K}$ & $T=298.15 \mathrm{~K}$ & $T=303.15 \mathrm{~K}$ & $T=308.15 \mathrm{~K}$ & \\
\hline \multicolumn{6}{|c|}{ PG } \\
\hline 0.01000 & -0.04 & 0.01 & 0.05 & 0.10 & 0.01 \\
\hline 0.03000 & -0.05 & 0.00 & 0.06 & 0.12 & 0.01 \\
\hline 0.05000 & -0.09 & 0.00 & 0.09 & 0.18 & 0.02 \\
\hline \multicolumn{6}{|c|}{$\mathrm{HG}$} \\
\hline 0.01000 & 0.02 & 0.01 & -0.01 & -0.02 & 0.00 \\
\hline 0.03000 & -0.08 & -0.03 & 0.02 & 0.06 & 0.01 \\
\hline 0.05000 & -0.11 & -0.04 & 0.02 & 0.08 & 0.01 \\
\hline
\end{tabular}

${ }^{a} m_{B}$ is the molality aqueous of niacin. 


\subsection{Partial molar isentropic compression of transfer}

The partial molar isentropic compression of transfer $\left(K_{\phi, S}^{0}\right)$ for all glycols in aqueous niacin solution from water at infinite dilution were evaluated using the following formula$\Delta K_{\phi, S}^{0}=K_{\phi, S}^{0}\left(\right.$ in aqueous niacin)- $K_{\phi, S}^{0}$ (in water)

In Table S4 the $\Delta K_{\phi, S}^{0}$ values are listed and it can be seen that the values are all positive throughout the temperature as well as over the entire range of niacin concentrations. These positive $\Delta K_{\phi, S}^{0}$ values refers to the interactions among the molecules of niacin and glycols which dominates the structure making capability of solute. This tendency of structure making of solute increases with the upsurge in the concentration of niacin. This makes the solution molecules less compressible as compared to the pure solvent molecules. This results in the decrement of the compressibility with niacin concentrations. Therefore for negative $K_{\phi, S}^{0}$ values for glycols over multiple concentrations, positive $\Delta K_{\phi, S}^{0}$ values are obtained ${ }^{12-14}$.

\section{Table S4}

Partial molar isentropic compression transfer, $\Delta K_{\phi, s}^{0}$, of glycols in the aqueous solution of niacin at different temperatures.

\begin{tabular}{ccccc}
\hline${ }^{a} m_{B} /\left(\mathrm{mol} \cdot \mathrm{kg}^{-1}\right)$ & \multicolumn{4}{c}{$\Delta K_{\phi, s}^{0} \times 10^{15} /\left(\mathrm{m}^{3} \cdot \mathrm{mol}^{-1} \cdot \mathrm{Pa}^{-1}\right)$} \\
\cline { 2 - 4 } & $T=293.15 \mathrm{~K}$ & $T=298.15 \mathrm{~K}$ & $T=303.15 \mathrm{~K}$ & $T=308.15 \mathrm{~K}$ \\
\hline 0.01000 & 0.00 & 0.08 & 0.03 & 0.04 \\
0.03000 & 0.13 & 0.17 & 0.13 & 0.13 \\
0.05000 & 0.23 & 0.27 & 0.22 & 0.23 \\
0.01000 & 0.15 & $\mathrm{HG}$ & 0.04 \\
0.03000 & 0.26 & 0.07 & 0.02 & 0.11 \\
0.05000 & 0.36 & 0.15 & 0.12 & 0.21 \\
\hline
\end{tabular}

${ }^{a} m_{B \text { is }}$ the molality of aqueous niacin. 


\subsection{Pair and triplet interaction coefficients}

From the following equation the partial molar volume of transfer $\left(\Delta V_{\phi}^{0}\right)$ and partial molar isentropic compression of transfer $\left(\Delta K_{\phi}^{0}\right)$ from water to aqueous niacin solution can be calculated-

$\Delta V_{\phi}^{0}($ water to aqueous niacin solution $)=2 V_{A B} m_{B}+3 V_{A B B} m_{B}^{2}$

$\Delta K_{\phi}^{0}$ (water to aqueous niacin solution) $=2 K_{A B} m_{B}+3 K_{A B B} m_{B}^{2}$

here $A$ represent glycols and $B$ represent niacin and $m_{B}$ denotes the molality of the aqueous niacin solutions. The pair and triplet interaction coefficient are represented by the parameters $V_{A B}$ and $V_{A B B}$ for volume and $K_{A B}, K_{A B B}$ for isentropic compression, and are reported in Table S5 for all the temperatures. The pair and triplet coefficients were calculated upon the theory depicted by McMillan and Mayer ${ }^{15}$. This theory states that due to the interaction between pair or more solute molecules, the separation of effects is observed and thus gives rise to the interaction coefficient. Later it was furthermore discussed by Friedman and Krishnan ${ }^{16}$ and Franks et $\mathrm{al}^{17}$. They added up the consideration of solute-solute interactions in the solvation regions. The values of pair interaction coefficient $V_{A B}$ are negative except for PG it is positive at $308.15 \mathrm{~K}$ and for $\mathrm{HG}$ it is positive at $303.15 \mathrm{~K}$. Triplet interaction coefficient $V_{A B B}$ is all positive throughout all the temperatures for all glycols apart for three values which are mol in magnitude. While on the other hand, the pair interaction coefficient $K_{A B}$ are all positive for every temperature all over the glycol concentrations. In the case of the triplet coefficient, $K_{A B B}$ all the values are all positive except for three values. Due to positive values of pair interaction coefficients; it suggests the dominance of pairwise interaction in (niacin+ water) and (niacin+ water + glycols) mixtures for compressibility and volumetric measurements ${ }^{18,19}$. Following the sphere overlapping theory, the water molecules are released from the hydration co-spheres to the bulk when the occurred interaction doesn't favor bonding ${ }^{20}$. 


\section{Table S5}

Pair $\left(V_{A B}, K_{A B}\right)$ and triplet $\left(V_{A B B}, K_{A B B}\right)$ of glycols in aqueous solutions of niacin at different temperatures.

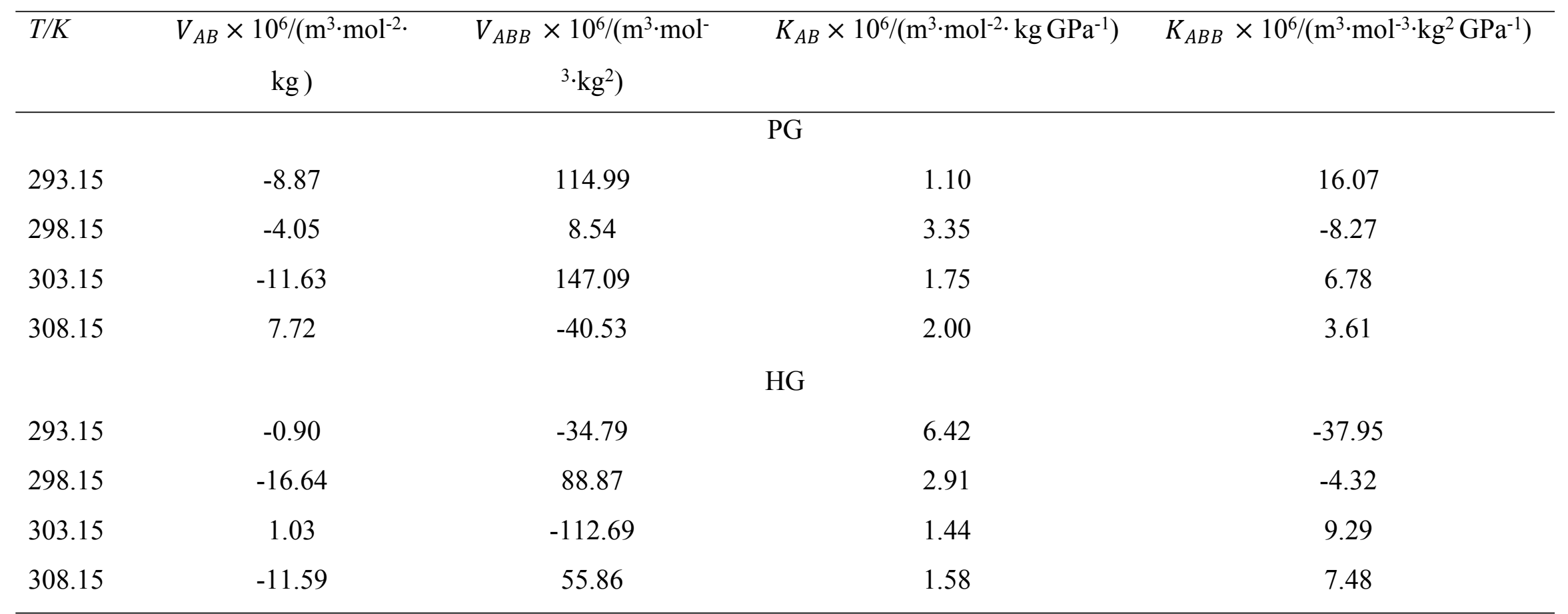

$T / K$ is the temperatures. 


\section{List of Tables}

\section{Table S1}

Partial molar volumes of transfer $\Delta V_{\phi}^{0}$, of glycols in the aqueous solution of niacin at different temperatures.

\section{Table S2}

Values of empirical parameters of Eq. 4, of glycols in aqueous solution of niacin at different temperatures.

\section{Table S3}

Partial molar expansibilities, $E_{\phi}^{0}$, for glycols in the aqueous solution of niacin at different temperatures.

\section{Table S4}

Partial molar isentropic compression transfer, $\Delta K_{\phi, s}^{0}$, of glycols in the aqueous solution of niacin at different temperatures.

\section{Table S5}

Pair $\left(V_{A B}, K_{A B}\right)$ and triplet $\left(V_{A B B}, K_{A B B}\right)$ of glycols in aqueous solutions of niacin at different temperatures.

\section{References:}

(1) Kaur, P.; Chakraborty, N.; Juglan, K.C.; Kumar, H. Volumetric, and ultrasonic studies of molecular interactions of glycols in aqueous glutaraldehyde solutions at different temperatures. J. Mol. Liq. 2020, 315, 1-12, https://doi.org/10.1016/j.molliq.2020.113763

(2) Tsierkezos, N. G.; Molinou, I. E. Thermodynamic properties of water+ ethylene glycol at 283.15, 293.15, 303.15, and 313.15 K.J. Chem. Eng. Data, 1998, 43, 989-993, https://doi.org/10.1021/je9800914

(3) Klimaszewski, K.; Stronka-Lewkowska, E.; Abramczyk, K.; Bald, A. Acoustic and volumetric studies on (triethylene glycol+ water) mixtures in a wide temperature range. $J$. Chem. Thermodyn. 2015, 89, 212-222, https://doi.org/10.1016/j.jct.2015.05.024

(4) Chakraborty, N.; Kumar, H.; Kaur, K.; Juglan, K. C. Acoustic and thermodynamic study of D-Panthenol in aqueous solutions of glycol at different temperatures. J. Chem. Thermodyn. 2018, 126, 137-146, https://doi.org/10.1016/j.jct.2018.07.006 
(5) Zafarani-Moattar, M.T.; Sarmad, S. Intermolecular interactions in mixtures of poly (ethylene glycol) with methoxybenzene and ethoxybenzene: Volumetric and viscometric studies. J. Chem. Thermodyn. 2010, 42, 1213-1221, https://doi.org/10.1016/j.jct.2013.12.008

(6) Kaur, K.; Juglan, K.C.; Kumar, H.; Behal, I. Volumetric and ultrasonic studies on interactions of ethylene glycol, diethylene glycol and triethylene glycol in aqueous solutions of glycerol at temperatures $\mathrm{T}=(293.15 \mathrm{~K}-308.15) \mathrm{K}$. J. Chem. Thermodyns. 2018, 125, 93106, https://doi.org/10.1016/j.jct.2018.05.016

(7) Chakraborty, N.; Kumar, H.; Kaur, K.; Juglan, K. C. Volumetric and Ultrasonic Studies on Interactions of Glycols in Aqueous Solutions of Xylitol at Different Temperatures. $J$. Chem. Eng. Data, 2020, 65, 1435-1446, https://doi.org/10.1021/acs.jced.9b00869

(8) Hepler, L; G. Can. Thermal expansion and structure in water and aqueous solutions $J$. Chem. 1969, 47, 4613-4617, DOI: 10.1139/v69-762

(9) Roy, M.N.; Dakua ,V.K.; Sinha, B. Partial Molar Volumes, Viscosity B-Coefficients, and Adiabatic Compressibilities of Sodium Molybdate in Aqueous 1,3-Dioxolane Mixtures from 303.15 to $323.15 \mathrm{~K}$, Int. J. Thermophys. 2007, 28, 1275-1284, DOI: 10.1007/s10765-0070220-0

(10) Kumar, H.; Behal, I. Volumetric and ultrasonic investigation of molecular interactions of L-serine and L-threonine in aqueous nicotinamide solutions at $\mathrm{T}=$ $\begin{array}{llllll}\text { (288.15-318.15) Kol. } & \text { K. } & \text { Liq. } & \text { 2016, } & \text { 219, } & \text { 756-764, }\end{array}$ https://doi.org/10.1016/j.molliq.2016.04.019

(11) Pradhan, P.; Shyam Sah, R.; Roy, M. N. Ion-solvent and ion-ion interactions of sodium molybdate and sodium tungstate in mixtures of ethane-1,2-diol and water at 298.15, 308.15 and 318.15 K. J. Mol. Liq. 2005, 149-154, https://doi.org/10.1016/j.molliq.2008.11.001

(12) Sadheghi, R.; Ziamajidi, F. Apparent molar volume and isentropic compressibility of trisodium citrate in water and in aqueous solutions of polyvinylpyrrolidone at $\mathrm{T}=(283.15$ to 308.15) K. J. Chem. Eng. Data 2007, 52, 1037-1044, https://doi.org/10.1021/je700001x

(13) Wadi, R. K.; Ramasami, P. Partial molal volumes and adiabatic compressibilities of transfer of glycine and DL-alanine from water to aqueous sodium sulfate at 288.15, 298.15 and 308.15 K. J. Chem. Soc., Faraday Trans. 1997, 93, 243-247, DOI: 10.1039/A604650I 
(14) Salabat, A.; Shamshiri, L.; Sahrakar, F. Thermodynamic and transport properties of aqueous trisodium citrate system at 298.15 K. J. Mol. Liq. 2005, 118, 67-70, https://doi.org/10.1016/j.molliq.2004.07.014

(15) Mcmillan, W.G.; Mayer, J.E. The statistical thermodynamics of multicomponent systems. J. Chem. Phys. 1945, 13, 276-305, https://doi.org/10.1063/1.1724036

(16) Krishnan, C. V.; Friedman, H. L. Enthalpies of alkyl sulfonates in water, heavy water, and water-alcohol mixtures and the interaction of water with methylene groups. J. Solution Chem. 1973, 2, 37-51, https://doi.org/10.1007/BF00645870

(17) Franks, F.; Pedley M.; Reid D.S. Solute interactions in dilute aqueous solutions. Microcalorimetric study of the hydrophobic interaction. J. Chem. Soc. Faraday Trans. 1976, 1, 359-367, https://doi.org/10.1039/F19767200359

(18) Kumar, H.; Behal, I. Volumetric, ultrasonic and UV absorption studies on interactions of antibiotic drug chloramphenicol with glycine and its dipeptide in aqueous solutions at $\mathrm{T}=$ (288.15-318.15) K. J. Chem. Thermodyn. 2016, 99, 16-29, https://doi.org/10.1016/j.jct.2016.03.040

(19) Kumar, H.; Behal, I.; Singla, M. Effect of L-serine and L-threonine on volumetric and acoustic behaviour of aqueous metformin hydrochloride solutions at $\mathrm{T}=(305.15,310.15$ and 315.15) K. J. Chem. Thermodyn. 2016, 95, 1-14, https://doi.org/10.1016/j.jct.2015.11.020.

(20) Iqbal, M.; Chaudhary, M.A. Effect of temperature on volumetric and viscometric properties of some non-steroidal anti-inflammatory drugs in aprotic solvents. J. Chem. Thermodyn. 2010, 42, 951-956, https://doi.org/10.1016/j.jct.2010.03.009 
